\author{
Kaori Morimoto*, BA, Alisha Harrington, BS, MAOM, Claudia Nelson, MS and \\ Brian Loveless, DO
}

\title{
Osteopathic approach to sacroiliac joint pain in pregnant patients
}

https://doi.org/10.1515/jom-2021-0231

Received September 21, 2021; accepted January 6, 2022; published online February 18, 2022

\begin{abstract}
This paper aims to provide a comprehensive review of the management of sacroiliac (SI) joint pain in pregnant patients. Although SI joint pain is highly prevalent among pregnant patients, the unique anatomy of the joint is rarely discussed in a clinical setting. This paper provides comprehensive review of the epidemiology, anatomy, alarm findings, standard treatment, osteopathic assessment, and osteopathic manipulative treatment (OMT) of the SI joint, and it provides a general and in-depth understanding of the SI joint pain in pregnant patients and its management.
\end{abstract}

Keywords: osteopathic manipulative medicine; pregnancy; SI joint pain.

Sacroiliac (SI) joint pain is one of the most prevalent causes of chronic low back pain and has been found to be the primary contributor of chronic low back pain $10-45 \%$ of the time [1-3]. SI joint pain can be highly debilitating both mentally and physically for many people [4]. The effect of SI joint pain on patients' quality of life who are presenting for minimally invasive surgical care is comparable to that of COPD, coronary heart disease, angina, asthma, and mild heart failure based on the study with EuroQol 5D (EQ-5D) and the Short Form (SF)-36-based health state utility values $(\mathrm{n}=198)[4]$.

Due to anatomical changes during pregnancy, such as observed increases in bodyweight, spinal lordosis,

\footnotetext{
*Corresponding author: Kaori Morimoto, BA, Western University of Health Sciences COMP-Northwest, 200 Mullins Drive, Lebanon, OR 97355, USA, E-mail: kaori.morimoto@westernu.edu. https://orcid. org/0000-0001-8674-7145

Alisha Harrington, BS, MAOM and Claudia Nelson, MS, Western University of Health Sciences COMP-Northwest, Lebanon, OR, USA. https://orcid.org/0000-0001-7387-8074 (A. Harrington). https://orcid.org/0000-0002-9296-3917 (C. Nelson) Brian Loveless, DO, Western University of Health Sciences COMP, Pomona, CA, USA. https://orcid.org/0000-0001-6735-0329
}

abdominal and intrauterine pressures due to the growth of the fetus, and laxity of the spine and pelvic structures due to the hormone relaxin, SI joint pain is prevalent in the pregnant female population [5-7]. In a study of 1,789 pregnant women in their third trimester, $22.6 \%$ of the women reported daily pelvic girdle pain. Among those patients, 53.8\% reported unilateral or bilateral SI joint pain. Furthermore, $2.8 \%$ of those who reported having SI joint pain suffered from daily symptoms up to two years post-delivery [5]. Therefore, medical providers need to understand the unique pathophysiology of the SI joint and all treatment options.

When the SI joint pain is due to the musculoskeletal etiology, assessing for somatic dysfunctions through the osteopathic lens and treating those with osteopathic manipulative treatment (OMT) can be highly beneficial for long- and short-term symptomatic relief [8]. Specifically for pregnant patients, many analgesics are contraindicated and utilized with caution [9]. Hence, OMT is an excellent alternative treatment for this unique population. In this paper, the current evidence for the use of OMT to treat SI joint pain in pregnant patients is reviewed.

\section{Clinical summary}

\section{SI joint pain in pregnancy and alarm findings}

Although most pregnancy-associated SI joint pain stems from a neuromusculoskeletal mechanism, certain obstetric and nonobstetric complications that manifest or mimic SI joint pain need to be ruled out to ensure proper diagnosis and treatment. Obstetric complications that manifest as or mimic SI joint pain include, but are not limited to, placental abruption, threatened abortion, chorioamnionitis, round ligament pain, nephrolithiasis, and pyelonephritis [10].

Some nonobstetric complications can be further categorized into systemic, neurologic, metabolic, and mechanical causes. For example, severe pain that is nonpositional and persists throughout the night should motivate the provider to rule out bone or soft tissue tumors and pelvic 
fractures [11-13]. A pelvic fracture is one of the top differential diagnoses for patients presenting with SI joint pain who are at high risk of osteoporosis, such as those with longterm steroid use. Further, patients with SI joint dysfunction secondary to previous pelvic trauma may have a worse prognosis [13].

If the associated SI joint pain increases with coughing or the Valsalva maneuver, further workup is warranted to identify possible neurological deficits such as cauda equina syndrome or a lumbar disk herniation. Similarly, a burning or an electric shocklike pain may be a pudendal nerve entrapment rather than a true SI joint dysfunction [13]. Additionally, SI joint pain manifesting with concomitant systemic symptoms such as fever, weight loss, and elevated erythrocyte sedimentation rate (ESR) are the typical signs of inflammatory arthritic conditions, including ankylosing spondylitis [3,13-15]. If such conditions are suspected based on the history and physical exam, necessary lab workups need to be ordered such as complete blood count, C-reactive protein, and ESR. Imaging studies, such as X-ray or HLA-B27 studies, may be necessary if history indicates seronegative arthritis [16]. Metabolic causes, such as infections or diabetic neuropathy, may present with SI joint pain, and workup for such conditions should be considered with reasonable suspicion $[13,17]$.

\section{Standard treatments of SI joint pain}

SI joint pain treatment goals include eliminating the cause of pain, restoring the proper mechanical integrity of the SI joint and the surrounding structures, and restoring the patient's daily functioning [18]. However, current treatments need to be properly considered and applied only to the appropriate patient populations. Regarding pregnancy, many of the current recommended treatments need to be modified in order to minimize unnecessary risk to the mother and fetus [7, 18].

Perhaps the most commonly touted treatment prescription for acute SI joint pain, defined as pain for a period of less than four weeks, the combination of ice, heat, rest, anti-inflammatory medications including non-steroidal anti-inflammatory drugs (NSAIDs), and mild mobilization has been found to be effective when treating the general population [19]. However, NSAIDs are generally not recommended for pregnant patients unless there is a specific indication for their use, such as in preventing preeclampsia or antiphospholipid antibody syndrome, or as a method for tocolysis in early pregnancy [19-21]. NSAIDs are contraindicated in pregnancy because they have been found to cross the placenta freely from the first trimester onwards, and are associated with multiple unwanted pregnancy outcomes [13]. The use of NSAIDs during the second trimester is associated with a small increased risk of cryptorchism in a male fetus, whereas NSAID use closer to the third trimester is associated with fetal renal injury, oligohydramnios, and premature closure of the ductus arteriosus [20, 21].

During the subacute phase, defined as pain lasting between 4 and 12 weeks, joint mobilization and physical therapy can be beneficial [22-24]. A pelvic belt is a safe alternative to medication for pregnant patients. However, the long-term use of those pain management therapies without addressing the actual cause of the SI joint pain is generally not recommended [19, 25, 26].

When reviewing treatment for the general population, if the patient's pain is severe and becomes chronic, defined as being present for six weeks or longer, imaging such as X-ray or MRI should be utilized to determine the etiology. Once nonmechanical causes are ruled out, physical therapy with a focus on core-strengthening training, as well as prescribed and monitored weight loss in obese patients, can be beneficial [26]. More aggressive interventions should be considered for the general population who suffer from refractory SI joint pain, including corticosteroid injections, but the etiology of the back pain should be reinvestigated to ensure it is originating from the SI joint specifically; if instead the pain is found to be originating from the lumbar spine, treatments such as radiofrequency ablative therapy, spinal cord stimulators, kyphoplasty, transcutaneous electrical nerve stimulation units, and surgical interventions, including laminectomies, discectomies, and spinal fusions, may need to be considered [26].

Regarding the pregnant population specifically, it has been determined that the majority of SI joint pain during pregnancy is transient in nature due to the joint laxity that occurs, therefore more conservative treatments are preferred to minimize risks for the fetus [10]. Surgical interventions should not be considered unless the pain continues postpartum and proves refractory to conservative treatments [7].

\section{Osteopathic assessments and treatments for somatic dysfunctions in pregnant patients}

OMT can be utilized safely and effectively during the acute and chronic phases of SI joint dysfunction to aid recovery, as well as during pregnancy [27]. Licciardone and colleagues [27] found OMT to be effective in reducing third trimester low back pain and associated functional decline 
compared to sham treatments. As one of the tenets of osteopathy indicates, our body is a structural, functional, and physiological unit. Therefore, full assessment of the patient is essential for effective treatment. The protocol described here is utilized by one of the authors and requires approximately $15 \mathrm{~min}$ to diagnose and treat somatic dysfunctions of the whole musculoskeletal system. The global musculoskeletal system assessment is recommended when a patient presents with SI joint pain in order to properly identify the potential etiology as well as treat any associated somatic dysfunctions, specifically those related to the hips, hamstrings, or quadriceps, because they have been found to be particularly prevalent in the pregnant population $[28,29]$.

\section{Part I: Patient lateral recumbent}

(1) Bilateral hip circumduction

(2) Lumbosacral joint decompression

(3) Pelvic diaphragm (assessment and treatment)

(4) Lumbar soft tissue treatment

(5) Rib raising (assessment and treatment)

(6) Thoracic diaphragm (assessment and treatment)

(7) Thoracic soft tissue treatment

(8) Cervical somatic dysfunction diagnosis

(9) Cranial somatic dysfunction diagnosis

\section{Part II: Patient seated}

(1) Thoracic inlet (assessment and treatment)

(2) Cardinal ligament dysfunction diagnosis (assessment and treatment)

\section{Discussion}

\section{SI joint anatomy overview}

The SI joint is a diarthroidial joint that articulates the sacrum and ilium [30, 31]. It is the largest axial joint in the body, and its central role is to transfer load between the spine and the lower extremities [30,31]. It also economizes the gait by reducing shock, absorbing stress, and sharing forces. Furthermore, the flexibility of the SI joint during pregnancy is crucial for vaginal delivery [32].

The hyaline cartilage of the sacrum, proximal third of the hyaline cartilage of the ilium, and the surrounding stabilizing ligaments form the fibrocartilage of the SI joint [33]. The dorsal aspect of the distal third portion of the SI joint fibrocartilage allows for the formation of an L-shaped synovial joint [33]. Therefore, the synovial joint itself is freely mobile, whereas the mobility of the fibrocartilage is minimal [34].

The anatomical configuration of the SI joint is highly variable in each individual [35]. In a radiographical study of 534 individuals without known SI joint disease, a Philips LX CT scanner was utilized to analyze the anatomic variation of the SI joint. Six variants were observed, the most common being an accessory SI joint [35]. The accessory joint forms at the posterosuperior portion of the SI joint at the level of the S1 and S2 foramina. This accessory joint was observed in approximately $20 \%$ of the study population, and the risk factors for formulating this joint were obesity and age older than 60 years [35]. Recognizing these variants in imaging studies may be helpful when determining the etiology of chronic and refractory SI joint pain in patients and when assessing one's susceptibility for SI joint pain during pregnancy.

\section{Joint stability}

The SI joint follows a force closure model characterized by the bony extensions protruding into the SI joint from both the sacral and iliac articular surfaces, forming a tight, blunted, interlocking structure that provides a high surface friction coefficient [32]. This unique structure combined with extensive ligamental stabilization enables the SI joint to maintain vertical stability without extra forces from the surrounding musculature [32].

The pelvic bone, composed of an interior of trabeculated bone surrounded by a shell of cortical bone, follows the structural sandwich model, an engineering term describing a high-strength system composed of thin facings with low-density cores [36]. This model is utilized in a variety of constructions and allows the material to withstand multiples of its weight. During the loading phase, the stress on the cortical surface of the pelvic bone measures approximately 50 times higher than the measured stress on the trabecular bone underneath [36]. This force transfers smoothly along the superior edge of the acetabulum onto the pelvis, then toward the SI joint and the pubic symphysis [36].

Some suggest that the coupling of the latissimus dorsi with the contralateral gluteus maximus muscle via the thoracolumbar fascia also plays a role in stabilizing the SI joint [37]. It is the combination of the characteristic biomechanical model of the pelvic bones and the stabilization from the surrounding ligaments and musculature that maintains the integrity of the SI joints. 


\section{Ligaments}

Unlike any other joint in the body, the SI joint is extensively stabilized with multiple ligaments anteriorly, posteriorly, and within the joint itself [38]. This complex anatomy enables the SI joint to effectively transfer the load between the spine and lower extremities [38]. Anteriorly, the SI joint connects to the anterior SI ligament, which connects the iliac fossa and the superior aspect of the sacrum [39]. Posteriorly, the SI joint is stabilized by the posterior SI, sacrospinous, and sacrotuberous ligaments [39].

The posterior SI ligament can be further divided into three parts: short (superior), long (inferior), and interosseous sections [40]. The short posterior SI ligament spans the entire length of the sacrum and inserts onto the ilium over the SI joint. The long posterior SI ligament is closely associated with the erector spinae muscles, thoracolumbar fascia, and sacrotuberous ligament [20]. During pregnancy, the long posterior SI ligament tends to be stretched due to the progressive increasing of the lumbar lordotic curve [41]. The interosseus SI ligaments are short, strong fibers that reside the deepest and serve to further stabilize the SI joint to withstand the axial load and strain created by the low back and lower extremities [40].

Although the uterosacral ligament does not involve the SI joint, it is crucial to be aware of this extra ligament in the female pelvis. The uterosacral ligament is $12-14 \mathrm{~cm}$ long and helps suspend the uterus in the pelvic cavity by connecting it to the sacrum [42]. Its distal portion, attached to the cervix and upper vagina, is the thickest and ranges from 0.5 to $2 \mathrm{~cm}$ [43]. The proximal section inserts onto the second to fourth sacral vertebrae and forms the lateral boundaries of the pouch of Douglas [42, 43]. During pregnancy, the length of the uterosacral ligament increases over time although a precise mechanism has not yet been identified [44].

\section{Surrounding musculature}

Although there is no muscle directly working across the SI joint, it has an intimate relationship with some of the largest muscle groups of the body. The movement of the SI joint is influenced by gravity and the muscles of the low back, trunk, and lower extremities rather than the active movement of the sacrum itself [37]. The major muscles that impact the movement of the SI joint include the erector spinae muscles, gluteus maximus, deep abdominal muscles, piriformis, biceps femoris, iliacus, and pelvic floor muscles [37].

The erector spinae muscles, along with the thoracolumbar fascia and the gluteus maximus, serve to stabilize the SI joint from the posterior aspect, whereas the deep abdominal muscles aid the forced closure of the SI joint, which is discussed in the "Joint Stability" section above [41]. The piriformis attaches to the anterior sacrum and the greater trochanter and aids hip abduction and external rotation when the hip is at a neutral position. When the hip is flexed, however, it becomes an internal rotator. Somatic dysfunction of piriformis can affect the sacram motion during those motions, which translates to the SI joint pain [42]. The biceps femoris attaches to the ipsilateral sacrotuberous ligament and induces posterior movement of the sacral base upon contraction, and the iliacus aids the synchronous movement of the pelvis during sacral nutation [41]. Finally, the pelvic floor muscles support the organs and aid in sacral extension [41].

During pregnancy, muscles such as the rectus abdominus and the internal and external oblique muscles become thinner compared to those of nonpregnant individuals $(n=156)$ [45]. The mechanism is not well understood, but musculoskeletal changes secondary to the pregnancy would be one of the contributing factors [45]. In general, there is limited data regarding musculature changes as the gravida uterus grows and how these changes affect the mobility of or pain in the SI joint.

\section{Craniosacral motion}

Regarding sacral nutation and counter nutation, the dura mater of the cauda equina attaches to the sacral canal at S2, enabling the synchronous movements of the sphenoid and occipital bones and the sacrum [46]. The motion and somatic dysfunctions in any of these structures can contribute to restrictions in SI joint mobility [47]. Additionally, the female anatomy contributes to the increased susceptibility of craniosacral dysfunction due to trauma and pregnancyrelated changes. As a result of uterine malposition secondary to scarring or large fibroids, the fascial drag can exacerbate craniosacral dysfunction, specifically that of hypernutation of the sacrum [48]. Hypernutation puts tension on the broad ligaments and fascia, creating reciprocal tension on the membranes of the central nervous system [48]. During pregnancy or menses, this can occur bilaterally, and a double occipitomastoid lesion is often found [48]. Therefore, when a pregnant patient presents with SI joint dysfunction or sacral pain, it is recommended to check for associated cranial dysfunctions.

\section{Joint mobility}

Due to the unique anatomy of the SI joint, the reported motion of the joint in a healthy individual is limited and 
Table 1: Collection of pregnancy-safe osteopathic manipulative treatments for sacroiliac joint pain.

\begin{tabular}{|c|c|}
\hline Osteopath & Mechanism of action \\
\hline $\begin{array}{ll}\text { Myofascial release techniques } \\
- & \text { Cervical, thoracic, lumbar lesions [68] } \\
- & \text { Cranial } \\
- & \text { Cardinal ligaments } \\
- & \text { Round ligaments } \\
- & \text { Uterus }\end{array}$ & $\begin{array}{l}\text { Alter sensory information from proprioceptive fibers in regional myofascial tissues, leading to an } \\
\text { attenuation in the efferent limb of the myostatic reflex, causing positive change in muscle and } \\
\text { myofascial tension }\end{array}$ \\
\hline $\begin{array}{ll}\text { Balanced ligamentous tension and joint } \\
\text { decompression techniques } \\
-\quad \text { OA joint [68] } \\
-\quad \text { Lumbosacral joint } \\
-\quad \text { SI joint } \\
-\quad \text { Pubic symphysis }[68,69] \\
-\quad \text { Sacral release }[68,69]\end{array}$ & $\begin{array}{l}\text { Balance the various forces across an articular surface to improve physiologic functioning of } \\
\text { respiration and postural proprioception }\end{array}$ \\
\hline $\begin{array}{l}\text { Muscle energy techniques } \\
-\quad \text { Pelvis: shear, flare, rotation } \\
-\quad \text { Sacrum: torsion, } \\
\text { flexion/extension }\end{array}$ & $\begin{array}{l}\text { Improve local circulation and respiratory function by decreasing edema and passive congestion, } \\
\text { which balances the neuromuscular junction and positively alters muscle tone }\end{array}$ \\
\hline $\begin{array}{ll}\text { Cranial techniques [69] } \\
- & \text { Dural sinus drainage } \\
- & \text { Dural stretch } \\
- & \text { V-spread } \\
-\quad & \text { Compression of the fourth ventricle } \\
& \text { (CV4) [68] }\end{array}$ & $\begin{array}{l}\text { Optimize fluid pressures within the cranium and dura by increasing compliance of the articular } \\
\text { sutures between the cranial bones as well as through manipulation of the sacrum and augmentation } \\
\text { of the craniosacral myodural bridge }[70,71]\end{array}$ \\
\hline $\begin{array}{ll}\text { Counterstrain techniques } \\
- & \text { Thoracic, lumbar, pelvic, and sacral } \\
& \text { lesions } \\
-\quad & \text { Psoas and quadratus lumborum } \\
& \text { (contralateral side of AT 10) } \\
-\quad \text { Inguinal ligament }\end{array}$ & $\begin{array}{l}\text { Hold strained muscles and connective tissue in their respective position of ease, leading to an } \\
\text { interruption of inappropriate nociceptive and proprioceptive activity by reducing the afferent } \\
\text { neuronal activity that facilitates central and peripheral sensitization }\end{array}$ \\
\hline $\begin{array}{l}\text { Articulatory techniques }[68] \\
-\quad \text { Thoracic } \\
-\quad \text { Sacroiliac }\end{array}$ & $\begin{array}{l}\text { Stretch restricted muscles, ligaments, and capsules to increase circulation, lymphatic flow, and } \\
\text { respiratory mechanics while decreasing myofascial tissue tension }\end{array}$ \\
\hline $\begin{array}{l}\text { Soft-tissue techniques [68] } \\
-\quad \text { Cervical } \\
-\quad \text { Scapulothoracic } \\
-\quad \text { Lumbar }\end{array}$ & $\begin{array}{l}\text { Provide a general state of tonic stimulation, leading to improved oxygenation, metabolic waste } \\
\text { removal, and relaxation of regional hypertonic fascia and connective tissues. }\end{array}$ \\
\hline $\begin{array}{l}\text { Facilitated position releases lymphatic } \\
\text { techniques }\end{array}$ & $\begin{array}{l}\text { Interrupt inappropriate gamma neuron firing in intrafusal muscle fibers to decrease overall excit- } \\
\text { atory afferent tone and local hypertonicity }\end{array}$ \\
\hline $\begin{array}{l}\text { Cervical, thoracic, and lumbar } \\
\text { lesions }\end{array}$ & \\
\hline $\begin{array}{ll}\text { Lymphatic techniques } \\
- & \text { Thoracic inlet [68] } \\
-\quad \text { Thoracic and pelvic diaphragm [68] } \\
-\quad \text { Lower extremity }\end{array}$ & $\begin{array}{l}\text { Reduce local myofascial restrictions on regional lymphatic structures, leading to decreased protein } \\
\text { accumulation and improved resorption of fluid }\end{array}$ \\
\hline
\end{tabular}

OA, osteoarthritic; SI, sacroiliac.

varies between less than $1^{\circ}$ and $6^{\circ}$ in the transverse or sagittal planes. Currently, there is no consensus on the degrees of normal SI joint mobility [30, 42, 49, 50]. As previously mentioned, gravity and the muscles of the low back, trunk, and lower extremities are the main drivers of SI joint motion instead of active sacral movements [37].

The normal mobility range also differs based on biological sex. For example, finite element models of the lumbar spine-pelvis-femur based on CT scans support the female pelvis permitting higher mobility and can withstand higher stresses, loads, and ligamental strains compared to the male pelvis [51].

In general, females have a wider sacral notch and a more backward-tilted sacrum that males [41]. Additionally, in their twenties, women develop the paraglenoidal sulcus, which is a groove in the iliac bone adjacent to the SI joint, 
whereas men do not [38]. These differences contribute to the higher incidence of SI joint misalignment in women of childbearing age. One retrospective study of the adolescent population showed that over two-thirds of the patients with low back pain secondary to SI joint misalignment were female $(n=48)[38,52]$.

Postmortem and $\mathrm{X}$-ray studies of the pelvis in pregnant women in the early 20th century clearly demonstrated increased SI joint mobility and widening of the symphysis $[53,54]$. More recently, one study showed a more than twofold increase in the prevalence of severe pregnancy-related pelvic pain at 36 weeks gestation in women with asymmetric right-left SI joint laxity compared to those without asymmetric laxity [55]. This illustrates how certain OMT techniques could be beneficial to reduce such asymmetry and provide symptomatic relief in pregnant patients.

\section{Innervation}

The SI joint has a rich innervation with nociceptive fibers that are responsive to calcitonin gene-related peptide (CGRP) and substance P [56]. Those immunoreactive free nerve endings exist in the anterior interosseous ligaments [56]. Additionally, the thick and formed nerve bundles were more frequently observed in dense and loose connective tissues, whereas the thin single-stranded nerve fibers reside near the blood vessels around the SI joint [56]. The SI joint has a proprioceptive innervation to provide feedback to the brain. The mechanoreceptors and the free nerve endings at the SI joint send the signal through the dorsal column [57].

The origin of those nerve fibers is controversial [58]. In the early to mid-20th century, the nerves innervating the SI joint were thought to have originated from the dorsal rami of S1 and S2, and from the superior gluteal and obturator nerves stemming from the sacral plexus. Additionally, Cunningham [59] and Nakagawa [60] reported the involvement of the ventral rami of $\mathrm{L} 4$ and $\mathrm{L} 5$, and the dorsal rami of L5. However, later studies suggest otherwise.

Grob et al. [61] reported that the sacral nerve branches were derived exclusively from the dorsal rami of S1 through S4 nerves and denied the presence of the branches from the obturator nerve or sacral plexus. Cox et al. [62] proposed a small contribution from the L4 and L5 ventral rami but denied a contribution from the obturator, femoral, and lumbosacral plexus nerves for anterior SI joint innervation. Bernard Jr [63] reported broad involvement of the lumbosacral nerves, including the L4 through S2 dorsal rami for the posterior segment and the L2 through S2 branches for the anterior segment of the SI joint, respectively. Although further study is required to understand each individual's innervation and anatomical variant, there is a consensus that the SI joint and the surrounding ligaments have extensive innervation that carry nociceptive information [56].

\section{Osteopathic manipulative treatment techniques for the SI joint pain in pregnant patients}

Manual therapy is a safe and effective evidence-based option for treating pregnant patients suffering from mechanical pelvic pain, including that of the SI joint [29, 64-67]. When pregnant patients have severe SI joint pain, the previously mentioned protocol can be followed with specific techniques, some of which have been gathered and presented in Table 1, to further alleviate the dysfunction and provide symptomatic relief. The limitations of these studies include their small sample size and their unrandomized control design.

\section{Conclusions}

SI joint pain is highly common among pregnant patients due to their rapidly changing anatomy and increased joint laxity. Therefore, understanding the mechanism of this pathophysiology and addressing the root cause in a noninvasive manner is critical for symptomatic relief, prevention of longterm somatic dysfunction, and improvement of the patients' day-to-day quality of life.

Research funding: None reported.

Author contributions: All authors provided substantial contributions to conception and design, acquisition of data, or analysis and interpretation of data; all authors drafted the article or revised it critically for important intellectual content; all authors gave final approval of the version of the article to be published; and all authors agree to be accountable for all aspects of the work in ensuring that questions related to the accuracy or integrity of any part of the work are appropriately investigated and resolved.

Competing interests: None reported.

\section{References}

1. Manchikanti L, Singh V, Pampati V, Damron KS, Barnhill RC, Beyer C, et al. Evaluation of the relative contributions of various structures in chronic low back pain. Pain Physician 2001;4: 308-16. Erratum in: Pain Phys 2002;5:114.

2. Liliang PC, Lu K, Liang CL, Tsai YD, Wang KW, Chen HJ. Sacroiliac joint pain after lumbar and lumbosacral fusion: findings using dual sacroiliac joint blocks. Pain Med 2011;91:1283-5. 
3. Cohen SP, Chen Y, Neufeld NJ. Sacroiliac joint pain: a comprehensive review of epidemiology, diagnosis and treatment. Expert Rev Neurother 2013;13:99-116.

4. Cher D, Polly D, Berven S. Sacroiliac joint pain: burden of disease. Med Dev 2014;7:73-81.

5. Albert H, Godskesen M, Westergaard J. Prognosis in four syndromes of pregnancy-related pelvic pain. Acta Obstet Gynecol Scand 2001;80:505-10.

6. Berg G, Hammar M, Möller-Nielsen J, Lindén U, Thorblad J. Low back pain during pregnancy. Obstet Gynecol 1988;71:71-5.

7. Fiani B, Sekhon M, Doan T, Bowers B, Covarrubias C, Barthelmass M, et al. Sacroiliac joint and pelvic dysfunction due to symphysiolysis in postpartum women. Cureus 2021;13:e18619.

8. Licciardone JC, Buchanan S, Hensel KL, King HH, Fulda KG, Stoll ST. Osteopathic manipulative treatment of back pain and related symptoms during pregnancy: a randomized controlled trial. Am J Obstet Gynecol 2010;202:43.e1-8.

9. Siu SS, Yeung JH, Lau TK. An in-vivo study on placental transfer of naproxen in early human pregnancy. Hum Reprod 2002;17: 1056-9.

10. Hacker NF, Gambone JC, Hobel CJ. Hacker \& Moore's essentials of obstetrics and gynecology. Philadelphia, PA: Elsevier; 2016.

11. Raj MA, Ampat G, Varacallo M. Sacroiliac joint pain. [Updated 2020 Sep 3]. In: StatPearls [Internet]. Treasure Island (FL): StatPearls Publishing; 2020.

12. Coccolini F, Stahel PF, Montori G, Biffl W, Horer TM, Catena F, et al. Pelvic trauma: WSES classification and guidelines. World J Emerg Surg 2017;12:5.

13. Le Huec JC, Tsoupras A, Leglise A, Heraudet P, Celarier G, Sturresson B. The sacro-iliac joint: a potentially painful enigma. Update on the diagnosis and treatment of pain from microtrauma. Orthop Traumatol Surg Res 2019;105:S31-42.

14. Dydyk AM, Forro SD, Hanna A. Sacroiliac joint injury. [Updated 2020 Oct 24]. In: StatPearls [Internet]. Treasure Island (FL): StatPearls Publishing; 2020.

15. Vyskocil JJ, Mcllroy MA, Brennan TA, Wilson FM. Pyogenic infection of the sacroiliac joint. Case reports and review of the literature. Medicine (Baltim) 1991;70:188-97.

16. van den Berg R, de Hooge M, Rudwaleit M, Sieper J, van Gaalen F, Reijnierse M, et al. ASAS modification of the Berlin algorithm for diagnosing axial spondyloarthritis: results from the SPondyloArthritis Caught Early (SPACE)-cohort and from the Assessment of SpondyloArthritis International Society (ASAS)cohort. Ann Rheum Dis 2013;72:1646.

17. Jende JME, Kender Z, Rother C, Alvarez-Ramos L, Groener JB, Pham M, et al. Diabetic polyneuropathy is associated with pathomorphological changes in human dorsal root ganglia: a study using 3T MR neurography. Front Neurosci 2020;14:570744.

18. Schmidt GL, Bhandutia AK, Altman DT. Management of sacroiliac joint pain. J Am Acad Orthop Surg 2018;26:610-6.

19. Siu SS, Yeung JH, Lau TK. An in-vivo study on placental transfer of naproxen in early human pregnancy. Hum Reprod 2002;17: 1056-9.

20. Kristensen DM, Hass U, Lesné L, Lottrup G, Jacobsen PR, Desdoits-Lethimonier $\mathrm{C}$, et al. Intrauterine exposure to mild analgesics is a risk factor for development of male reproductive disorders in human and rat. Hum Reprod 2011;26:235-44.

21. Bloor $M$, Paech $M$. Nonsteroidal anti-inflammatory drugs during pregnancy and the initiation of lactation. Anesth Analg 2013;116: 1063-75.
22. Mitchell B, MacPhail T, Vivian D, Verrills P, Barnard A. Abstract: diagnostic sacroiliac joint injections: is a control block necessary? J Sci Med Sport 2015;12(2 Suppl):e5-6.

23. Mitchell DA, Esler DM. Pelvic instability - painful pelvic girdle in pregnancy. Aust Fam Physician 2009;28:409-10.

24. DonTigny RL. Function and pathomechanics of the sacroiliac joint. A review. Phys Ther 1985;65:35-44.

25. Hammer N, Möbius R, Schleifenbaum S, Hammer KH, Klima S, Lange JS, et al. Pelvic belt effects on health outcomes and functional parameters of patients with sacroiliac joint pain. PLoS One 2015;10:e0136375. Erratum in: PLoS One 2015;10:e0140090.

26. Casiano VE, Dydyk AM, Varacallo M. Back pain. 2021 May 12. In: StatPearls [Internet]. Treasure Island (FL): StatPearls Publishing; 2021.

27. Licciardone JC, Buchanan S, Hensel KL, King HH, Fulda KG, Stoll ST. Osteopathic manipulative treatment of back pain and related symptoms during pregnancy: a randomized controlled trial. Am J Obstet Gynecol 2010;202:43.e1-8.

28. Oswald C, Higgins CC, Assimakopoulos D. Optimizing pain relief during pregnancy using manual therapy. Can Fam Physician 2013;59:841-2.

29. Task Force on the Low Back Pain Clinical Practice Guidelines. American Osteopathic Association guidelines for osteopathic manipulative treatment (OMT) for patients with low back pain. J Am Osteopath Assoc 2016;116:536-49.

30. Foley BS, Buschbacher RM. Sacroiliac joint pain: anatomy, biomechanics, diagnosis, and treatment. Am J Phys Med Rehabil 2006;85:997-1006.

31. Weisl H. The movements of the sacroiliac joint. Acta Anat 1955;23: 80-91.

32. Vleeming A, Schuenke M. Form and force closure of the sacroiliac joints. Pharm Manag PM R 2019;11(1 Suppl):S24-31.

33. Puhakka KB, Melsen F, Jurik AG, Boel LW, Vesterby A, Egund N. MR imaging of the normal sacroiliac joint with correlation to histology. Skeletal Radiol 2004;33:15-28.

34. Oda H. Structure and function of the synovial joint. Nihon Rinsho 2005;63(1 Suppl):75-9.

35. Prassopoulos PK, Faflia CP, Voloudaki AE, Gourtsoyiannis NC. Sacroiliac joints: anatomical variants on CT. J Comput Assist Tomogr 1999;23:323-7.

36. Dalstra M, Huiskes R. Load transfer across the pelvic bone. J Biomech 1995;28:715-24.

37. Ombregt L, Bisschop P, Ter Veer HJ. Applied anatomy of the sacroiliac joint. In: Ombregt L, Bisschop P, Ter Veer HJ, editors. A system of orthopedic medicine. London, England: W.B. Saunders; 1995, vol 694:594-610 pp.

38. Vleeming A, Schuenke MD, Masi AT, Carreiro JE, Danneels L, Willard FH. The sacroiliac joint: an overview of its anatomy, function and potential clinical implications. J Anat 2012;221: 537-67.

39. Netter FH, G. MCA, Hansen JT. Atlas of human anatomy. Philadelphia, PA: Elsevier; 2018.

40. Vleeming A, Pool-Goudzwaard AL, Hammudoghlu D, Stoeckart R, Snijders CJ, Mens JM. The function of the long dorsal sacroiliac ligament: its implication for understanding low back pain. Spine 1996;21:556-62.

41. Kiapour A, Joukar A, Elgafy H, Erbulut DU, Agarwal AK, Goel VK. Biomechanics of the sacroiliac joint: anatomy, function, biomechanics, sexual dimorphism, and causes of pain. Int J Spine Surg 2020;14(1 Suppl):3-13. 
42. Vu D, Haylen BT, Tse K, Farnsworth A. Surgical anatomy of the uterosacral ligament. Int Urogynecol J 2010;21:1123-8.

43. Scioscia M, Scardapane A, Virgilio BA, Libera M, Lorusso F, Noventa M. Ultrasound of the uterosacral ligament, parametrium, and paracervix: disagreement in terminology between imaging anatomy and modern gynecologic surgery. J Clin Med 2021; 10:437.

44. Jean Dit Gautier E, Mayeur O, Lepage J, Brieu M, Cosson M, Rubod C. Pregnancy impact on uterosacral ligament and pelvic muscles using a 3D numerical and finite element model: preliminary results. Int Urogynecol J 2018;29:425-30.

45. Weis CA, Triano JJ, Barrett J, Campbell MD, Croy M, Roeder J. Ultrasound assessment of abdominal muscle thickness in postpartum vs. nulliparous women. J Manip Physiol Ther 2015;38: 352-7.

46. Basit H, Reddy V, Varacallo M. Anatomy, back, spinal nervemuscle innervation. 2021 May 8. In: StatPearls [Internet]. Treasure Island (FL): StatPearls Publishing; 2021.

47. Seffinger MA, Hruby R, Licciardone J, Willard FH. Foundations of osteopathic medicine, 4th ed. Philadelphia, PA: Wolters-Kluwer; 2018.

48. Magoun HI. Osteopathy in the cranial field. United States: Sutherland Cranial Teaching Foundation; 1997:142-3 pp.

49. Jeong JH, Leasure JM, Park J. Assessment of biomechanical changes after sacroiliac joint fusion by application of the 3-dimensional motion analysis technique. World Neurosurg 2018;117:e538-43.

50. Nagamoto Y, Iwasaki M, Sakaura H, Sugiura T, Fujimori T, Matsuo $\mathrm{Y}$, et al. Sacroiliac joint motion in patients with degenerative lumbar spine disorders. J Neurosurg Spine 2015;23:209-16.

51. Joukar A, Shah A, Kiapour A, Vosoughi AS, Duhon B, Agarwal AK, et al. Sex specific sacroiliac joint biomechanics during standing upright: a finite element study. Spine 2018;43:E1053-60.

52. Stoev I, Powers AK, Puglisi JA, Munro R, Leonard JR. Sacroiliac joint pain in the pediatric population. J Neurosurg Pediatr 2012;9:602-7.

53. Abramson D, Roberts SM, Wilson PD. Relaxation of the pelvic joints in pregnancy. Surg Gynecol Obstet 1934;58:595-613.

54. Brooke R. The sacro-iliac joint. J Anat 1924;58:299-305.

55. Damen L, Buyruk HM, Guler-Uysal F, Lotgering FK, Snijders C), Stam HJ. Pelvic pain during pregnancy is associated with asymmetric laxity of the sacroiliac joints. Acta Obstet Gynecol Scand 2001;80:1019-24.

56. Szadek KM, Hoogland PV, Zuurmond WW, de Lange JJ, Perez RS. Nociceptive nerve fibers in the sacroiliac joint in humans. Reg Anesth Pain Med 2008;33:36-43.

57. Vilensky JA, O'Connor BL, Fortin JD, Merkel GJ, Jimenez AM, Scofield BA, et al. Histologic analysis of neural elements in the human sacroiliac joint. Spine 2002;27:1202-7.
58. Forst SL, Wheeler MT, Fortin JD, Vilensky JA. The sacroiliac joint: anatomy, physiology and clinical significance. Pain Physician 2006;9:61-7.

59. Cunningham DJ. Cunningham's text-book of anatomy. New York: Oxford University Press; 1931.

60. Nakagawa T. A study on the distribution of nerve fi laments of the iliosacral joint and its adjacent region in the Japanese. J Jpn Orthop Assoc 1966;40:419-30.

61. Grob KR, Neuhuber WL, Kissling RO. Die Innervation des Sacroiliacalgelenkes beim Menschen [Innervation of the sacroiliac joint of the human]. Z Rheumatol 1995;54:117-22.

62. Cox M, Ng G, Mashriqi F, Iwanaga J, Alonso F, Tubbs K, et al. Innervation of the anterior sacroiliac joint. World Neurosurg 2017; 107:750-2.

63. Bernard TN, Jr. The sacroiliac joint syndrome: pathophysiology, diagnosis, and management. In: Frymoyer JW, editor. The adult spine. Principles and practice. New York: Raven; 1991: 2107-30 pp.

64. Franke H, Franke JD, Belz SM, Fryer G. Osteopathic manipulative treatment for low back pain and pelvic girdle pain during and after pregnancy: a systematic review and meta-analysis. J Bodyw Mov Ther 2017;21:752-62.

65. Fryer G, Morse CM, Johnson JC. Spinal and sacroiliac assessment and treatment techniques used by osteopathic physicians in the United States. Osteopath Med Prim Care 2009;3:4.

66. Liddle SD, Pennick V. Interventions for preventing and treating low-back and pelvic pain during pregnancy. Cochrane Database Syst Rev 2015;2015:CD001139.

67. Schwerla F, Rother K, Rother D, Ruetz M, Resch KL. Osteopathic manipulative therapy in women with postpartum low back pain and disability: a pragmatic randomized controlled trial. J Osteopath Med 2015;115:416-25.

68. Hensel KL, Buchanan S, Brown SK, Rodriguez M, Cruser DA. Pregnancy research on osteopathic manipulation optimizing treatment effects: the PROMOTE study. Am J Obstet Gynecol 2015; 212:108.e1-9.

69. Elden H, Ostgaard HC, Glantz A, Marciniak P, Linnér A-C, Olsén MF. Effects of craniosacral therapy as adjunct to standard treatment for pelvic girdle pain in pregnant women: a multicenter, single blind, randomized control trial. Acta Obstet Gynecol Scand 2013;92:775-82.

70. Zheng N, Chung BS, Li YL, Liu TY, Zhang LX, Ge YY, et al. The myodural bridge complex defined as a new functional structure. Surg Radiol Anat 2020;42:143-53.

71. Department of Neuromusculoskeletal Medicine/Osteopathic Manipulative Medicine at Western University of Health Sciences. College of osteopathic medicine of the Pacific. Pomona, CA: The Expanding Osteopathic Concept; 2019:5-10 pp. 